\title{
TEMPO E HISTÓRIA NO PLANO DE AVENIDAS
}

\author{
Marisa Varanda Teixeira Carpintéro \\ Centro Interdisciplinar de Estudos da Cidade - Departamento de História, \\ Instituto de Filosofia e Ciências Humanas - UNICAMP
}

\begin{abstract}
No centro de Fedora, metrópole de pedra cinzenta, há um palácio de metal com uma esfera de vidro em cada cômodo. Dentro de cada esfera, vê-se uma cidade azul que é o modelo para uma outra Fedora. São as formas que a cidade teria podido tomar se, por uma razão ou por outra, não tivesse se tornado o que é atualmente. Em todas as épocas, alguém, vendo Fedora tal como era, havia imaginado um modo de transformá-la na cidade ideal, mas, enquanto construía o seu modelo em miniatura, Fedora já não era mais a mesma de antes e o que até ontem havia sido um possível futuro hoje não passava de um brinquedo numa esfera de vidro. (CALVINO, 1991:32)
\end{abstract}

Como nos filmes de ficção científica, muitos acreditaram que no que seria então o futuro, por volta do ano 2001, as cidades seriam totalmente diferentes. Os cenários da ficção científica eram referências para as imagens de uma época onde os espaços urbanos substituiriam suas históricas contradições por uma eficiente felicidade idealizada e sonhada, tendo em vista o alcance imaginado da tecnologia.

Existem em nossa imaginação viagens através dos filmes e da literatura ficcional, onde veículos aéreos cruzam os céus urbanos como bolhas de vidro e luz com pessoas transportadas neles e transitando em passarelas e túneis suspensos. As construções seriam como máquinas eficientes e funcionais, que a partir das suas mega-estruturas consagrariam a técnica e afastariam a possibilidade de uma natureza indomável. Esse caminho nos conduz ao mundo dos sonhos e das utopias como também nos aproximam das teorias urbanísticas, que desde o início do século, se colocavam no desafio de pensar o futuro das cidades. Todavia, hoje deparamos com uma gama de propostas de intervenção urbana, em que as palavras requalificação, reabilitação, revitalização, recuperação - e sem dúvida muitos outros "res" - se colocam na tentativa de reconstruir o que as práticas urbanísticas dos dois últimos séculos, em nome do progresso e da modernização foram capazes de destruir. Contudo, não se trata

URBANA, ano 2, no 2, 2007, Dossiê: Cidade, Imagem, História e Interdisciplinaridade. 
de avaliarmos aqui o mérito dos projetos de revitalização de centros de cidades, bairros, e recuperação de edificações históricas realizados nos últimos anos em várias cidades brasileiras, mas sim chamar a atenção dos historiadores no que se refere à apropriação da história e do tempo, feita pelos urbanistas, que ao desenhar o futuro, marcavam um novo tempo procurando garantir a legitimidade das transformações.

Ao percorrermos a leitura de diferentes Planos urbanísticos apresentados ao longo dos últimos séculos, constatamos de que forma a história se coloca como um aspecto importante para a legitimidade dos discursos. Além disso, percebemos como a arquitetura, ao longo desses anos, foi capaz de materializar através de seus projetos a releitura da história e em alguns casos em descompasso conceitual, com o próprio discurso urbanista. Esse artigo tem como objetivo descortinar essas discussões tomando como análise o Plano de Avenidas, elaborado, na década de 1930, pelo engenheiro Francisco Prestes Maia para a cidade de São Paulo (MAIA, 1930).

\section{A história da cidade no Plano de Avenidas}

Como todo urbanista, Prestes Maia não apenas projetou um espaço, mas também um tempo. Em cada capítulo de sua obra a história gravita como elemento fundante da disciplina urbanismo. Através dela se articulam os campos conceituais que tratam a cidade, ora como um ser vivo, ora como uma máquina. Além disto, a história é a fonte reprodutora capaz de permitir ao autor apresentar todas as suas facetas de poeta, artista, técnico e político. Ao se referir à cidade como um ser orgânico, o urbanista se coloca concomitantemente como um médico na tentativa de elaborar um diagnóstico, para o chamado mal urbano. Em sua opinião, o congestionamento, a aglomeração, as habitações insalubres, a inexistência de obras sanitárias, de iluminação, de água e a falta de esgotos são elementos incompatíveis com o desenvolvimento da cidade. Ainda no seu entender esse mal é universal e dele sofrem as grandes cidades. $O$ urbanista, assim como o médico, deverá servir-se da técnica para afastar e prevenir os males causados pela crise do crescimento desordenado.

URBANA, ano 2, no 2, 2007, Dossiê: Cidade, Imagem, História e Interdisciplinaridade. 
Entretanto, se a cidade é considerada como um corpo urbano, também como um corpo humano ela contém uma história. É no processo de interpretação dessa história que o urbanista elabora as suas projeções. Desse modo é ainda no interior do mesmo processo que podemos acompanhar estas diferentes etapas do plano: primeiramente o diagnóstico, em alguns casos os males são provenientes da má formação, em seguida o medicamento adequado, a previsão dos futuros problemas, o acompanhamento do seu desenvolvimento, e por fim o cuidado com a beleza.

A leitura histórica feita por Prestes Maia sobre a cidade de São Paulo é muito semelhante àquelas elaboradas pelos historiadores e memorialistas da época. Uma cidade pacata, sombria, provinciana, atrasada, e como ele diz ,"(...) com pouca coisa digna de ser vista pelo extrangeiro". Prestes Maia procura reforçar essas imagens a partir das gravuras e fotografias de diferentes épocas da cidade, com o intuito de estabelecer a dialética, passado-presente e futuro. Elas iniciam com o quadro de Fundação da cidade elaborado por Oscar Pereira da Silva, retratando a primeira missa no planalto de Piratininga. Em seguida vamos encontrar um desenho de 1628 do primeiro paço, que segundo o autor, foi uma reconstituição de Wasth Rodrigues, baseada no mapa de Céspedes quando este atravessou o Estado de São Paulo. São imagens apresentando pouco movimento, que retratam a cidade até o final do século XIX com algumas casas coloniais sem recuo, provavelmente construídas de pau-a-pique ou taipa de pilão, com sistema de cobertura de telhado de duas águas.

$\mathrm{O}$ aspecto humilde das construções se confunde com a natureza, como no bucólico cenário do Brás ou na conhecida foto das lavadeiras do Tamanduateí. o sentido de vida pacata podemos também extrair das fotos das antigas Chácaras (no então morro do Chá), ao lado da tranqüilidade das ruas e ladeiras, curvas e estreitas, decoradas com velhos lampiões. Todavia, tal como os historiadores, para justificar o crescimento da cidade, o autor procura resgatar no passado as imagens do presente, ao revelar o caráter desbravador do povo paulistano (CINTRA e MAIA, 1930: 56) No primeiro artigo da série publicada no Boletim de Engenharia, em 1924, o autor associa as etapas do desenvolvimento econômico de São Paulo à presença do bandeirante. "(...) de desbravador passou a sedentário, cultivador valente do solo, do qual fez surgir o oceano maravilhoso do café." Nessa caminhada do "progresso" não poderia faltar referências ao papel

URBANA, ano 2, no 2, 2007, Dossiê: Cidade, Imagem, História e Interdisciplinaridade. 
do imigrante e, por fim, a chegada das fábricas inaugurando uma nova era - a do industrialismo impulsionador de cidades.

O olhar do urbanista para o passado colonial é marcado pela euforia do presente, diante da aparente chegada do progresso. Este fenômeno, que segundo as interpretações históricas de Pierre Monbeig, Jaime Cortesão e Aroldo de Azevedo foi provocado pela energia da raça (bandeirantes e imigrantes), se coloca naquele momento como responsável pelas transformações urbanas. ${ }^{1} \mathrm{~A}$ partir daí as imagens ganham movimento e com a ajuda do texto procuram problematizar o presente. A cidade, no começo do século, apresenta um cenário bem diferente do anterior, ruas pavimentadas, casas e edifícios construídos em diferentes estilos arquitetônicos procuram demarcar o poderio econômico de seus habitantes. O teatro Municipal, o prédio Martinelli, a igreja de São Bento, a Estação da Luz, o Museu Paulista, Palácio das Indústrias. Todas essas construções, na perspectiva do autor, são valiosas enquanto forma e função, entretanto, se perdem no meio da desordem causada pelo crescimento urbano. Os exemplos estão nas fotos de uma garagem ao ar livre na Praça da Sé repleta de veículos que impossibilitam a circulação em uma área comercial; outras mostram a concentração excessiva de edifícios ou a ausência de áreas verdes, como o flagrante das Ladeiras do Ouvidor e São Francisco e da rua 15 de Novembro.

As fotos da inundação dos rios Tietê e Pinheiros, atingindo os Bairros de Bom Retiro e Pinheiros, no ano de 1929, procuram demonstrar o transtorno e o desperdício das áreas ribeirinhas. Enquanto as muralhas para as cidades européias significavam obstáculos para o seu crescimento, o dois rios foram os acidentes geográficos que a natureza ofereceu à cidade de São Paulo. Em cada página o autor recorre à história para justificar a eliminação dos vestígios do passado colonial; por outro lado constrói um presente problemático na tentativa de se desprender da história e buscar no itinerário de um sonho - as projeções de um novo tempo. Este é o ponto crucial de nossas explorações do Plano de Avenidas, pois é o instante da criação, em que o autor se vê diante da integração da razão com a paixão. Instante que se manifesta no discurso de outros urbanistas, dentre eles, o mestre Le Corbusier.

\footnotetext{
${ }^{1}$ Azevedo, 1958, Mobeig, 1958, Cortesão, 1958.
}

URBANA, ano 2, no 2, 2007, Dossiê: Cidade, Imagem, História e Interdisciplinaridade. 
O trabalho da razão adiciona-se sem cessar, a sua curva é ascencional; ele cria o instrumental; é o que chamamos de progresso. Os sentimentos da paixão são constantes: São baixos ou elevados entre duas cotas que os milênios não mudaram. Podemos arriscar a hipótese de que as grandes obras emotivas, obras de arte, nascem da integração bem sucedida da paixão e do conhecimento. (LE CORBUSIER, 1992: 43)

\section{A história como inspiração}

No Plano de Avenidas encontramos esta integração nas imagens projetadas para o futuro. O discurso teórico produz imagens que se pretendem inovadoras, pois ao se desprenderem da história inauguram um outro tempo marcado pelos princípios e orientações técnicas concedidas pela disciplina urbanismo. Entretanto, no plano visual a linguagem artística revela o encontro com o passado, além disso, apresenta um movimento diferente daquela racionalidade científica ao buscar na história a liberdade, o espírito criador. De acordo com Prestes Maia podemos reduzir as concepções de arte em três elementos: imitação, idealização e criação. A partir desses três elementos podemos, segundo Prestes Maia, compreender ainda que:

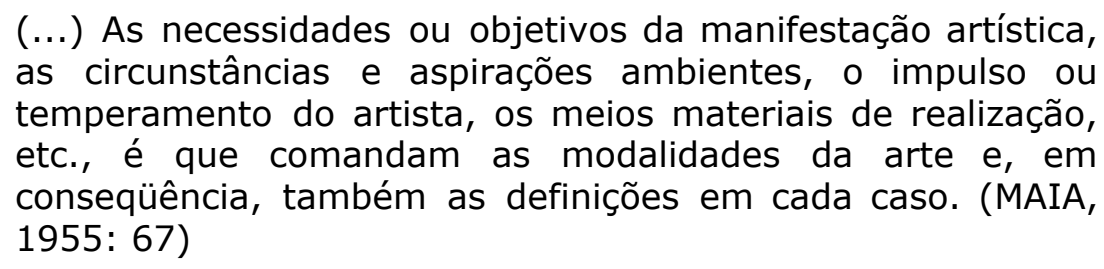

Neste sentido, cada um poderá dizer o que é o belo ou o que é a arte sem se prender aos conceitos gerais e universais como ocorre com a ciência. Segundo ele, muitos artistas, adotando pontos de partida imprecisos ou precipitados, e querendo depois trabalhar filosoficamente, acabam por praticar as maiores heresias. Além do mais, importa para ele ressaltar que o objetivo central da arte é transmitir o sentimento e ao mesmo tempo possibilitar o traço de união entre as criaturas, "(...) é o veículo mais eficiente e amável de idéias e mensagens humanas." (MAIA, 1955:67)

URBANA, ano 2, no 2, 2007, Dossiê: Cidade, Imagem, História e Interdisciplinaridade. 
Reconhece que a ciência e a "literatura discursiva" conseguem transmitir fatos e sabedoria, sendo entretanto inaptas à comunicação de sentimentos. Prestes Maia partilha uma opinião corrente também expressa por Lewis Mumford em seu livro Arte e Técnica, onde interpreta a linguagem expressiva da arte como:

[....] o lado interior e subjetivo do homem; todas as suas estruturas simbólicas são outros tantos esforços para inventar um vocabulário e uma linguagem através da qual o homem possa exteriorizar e projetar os seus estados íntimos e, mais particularmente, dar uma forma concreta e pública às suas emoções, sentimentos e intuições dos significados e valores da vida. (MUMFORD, 1952: 32)

Emoções e sentimentos também estão presentes no Plano de Avenidas, sendo a arquitetura o veículo simbólico capaz de evocá-los através da imponência dos edifícios cívicos, com sua aparência de solidez e beleza. Como já dissemos, estes efeitos foram extraídos da linguagem arquitetônica herdada do mundo antigo e aplicados na Renascença e em outras épocas. Podemos reconhecer essa linguagem em elementos, tais como, as colunas, pilastras, capitéis, cornijas, pórticos, frontão, arquitrave, frisos e em seus ornamentos. Essa linguagem aparece no Plano na forma de desenhos que parecem falar por si, diferente das longas e detalhadas explicações do texto escrito. Em cada página, pontes, viadutos, edifícios públicos, praças e monumentos ganham uma nova vestimenta, confeccionadas com os motivos da Renascença.

O Viaduto da Boa Vista foi contemplado com um arco triunfal romano emoldurado por pilastras e meias-colunas; na fachada, pilastras dóricas são marcadas pela presença de capitéis e base servindo de molduras para as figuras esculpidas dos Davis de Donatello e de Michelângelo; além disso, para completar o cenário destaca-se ao fundo a vista do Palácio do Governo. Como um poeta, Prestes Maia buscava no passado clássico as origens verdadeiras e imaculadas da beleza arquitetônica, com o intuito de sensibilizar a alma do leitor. Ao propor a abertura e o prolongamento da avenida Tabatinguera, artisticamente seu pincel desenha um espaço aberto ou

[...] percée fronteira à rua e à igreja da Boa Morte, no caso da reconstrução desta. Um dos desenhos exemplifica o tratamento do local. É porém cousa muito secundaria e

URBANA, ano 2, no 2, 2007, Dossiê: Cidade, Imagem, História e Interdisciplinaridade. 
sem outro fim que mostrar a conveniencia de estudar sempre em conjuncto os edifícios importantes, publicos ou não, e o local em que se elevam.(MAIA,1930:42.)

Neste espaço o artista evoca a beleza dos edifícios existentes, como a igreja da Boa Morte, e ainda oferece uma praça margeada de edifícios e em destaque uma parede rústica construída de pedra como no Cortille della Cavallerizza de Giulio Romano (1538-39). ${ }^{2}$ Uma outra maneira de difundir o gosto pela arte clássica foi espalhar pelos locais públicos da cidade reproduções de esculturas célebres, como o Davi de Miguelângelo (originalmente estava no Estádio do Pacaembu) e o Moisés desse mesmo artista (na galeria Prestes Maia), ou com a escultura de um cavaleiro romano no monumento em homenagem ao arquiteto Ramos de Azevedo nas margens do Tietê. Essas imagens procuravam transportar o observador a um foco central: o espaço servia como cenário para dar relevo aos edifícios que o cercavam.

Assim como nos estudos de Carl Schorscke em relação aos diferentes estilos arquitetônicos que predominaram em Viena no fim do século XIX, será que também a falta de uma tradição histórica levou este urbanista e artista a emprestar da antigüidade seus heróis? Para Viena, segundo Schorscke, os parlamentares austríacos preferiam compor seus edifícios com os heróis e símbolos da mitologia grega no sentido de representar a unidade liberal entre política e cultura racional. Ainda no seu entender os parlamentares,

[...] não se sentiram atraídos por uma figura tão carregada de um passado revolucionário como a Liberdade. Palas Atenas, protetora da pólis, deusa da sabedoria, era um símbolo mais seguro. Era também uma divindade adequada para representar a unidade entre política e cultura racional, unidade expressa pelo lema do iluminismo tantas vezes repetido... (SHORSCKE, 1988: 61)

Não podemos esquecer que a arquitetura expressa no Plano de Avenidas estava na verdade procurando dialogar com as recentes construções na cidade, dentre elas, o Mercado Municipal (1925-1933), o Palácio da Justiça (1920-1933), a Estação Sorocabana(1926-1938), a Catedral da Sé, a Faculdade de Medicina de São Paulo, o edifício Martinelli. E estes por sua vez representavam os conceitos e valores que predominavam na época - a monumentalidade como forma de

\footnotetext{
2 Consulta realizada na obras de Sumerson, John. A Linguagem Clássica da Arquitetura, São Paulo, Martins Fontes, 1994.p.49
}

URBANA, ano 2, no 2, 2007, Dossiê: Cidade, Imagem, História e Interdisciplinaridade. 
expressar o crescimento, a riqueza e o poder da sociedade industrial. Dessa maneira, não podemos deixar de ressaltar a preocupação do autor em registrar em meio às figuras romanas a bravura dos heróis paulistas. Não foi à toa que para estes heróis o autor escolheu as Pontes como local adequado para prestar-Ihes uma homenagem, pois ainda no seu entender elas caracterizam a individualidade das grandes Capitais.

As pontes de Paris, Roma, Florença, Veneza, etc. ligam-se indissoluvelmente á lembrança dessas cidades. Em Londres, de Blackfriars á Torre, ha a serie magnifica de estructuras e panoramas, que culminam em Westminster(...)Em Madrid el puente de Toledo interessa mais que todos os monumentos modernos. Tower Bridge, ponte Alexandre, Brooklyn, não obstante o ar de confiserie da primeira, os festões da segunda e a apparente instabilidade da terceira, são inolidaveis. Gard, Avignon, Toledo, Alcantara, etc, conhecem-se sobretudo por suas pontes. (MAIA, Prestes, 1930: 350)

A Ponte Grande será localizada no eixo da maior artéria paulista (avenida Tiradentes), será o mais importante acesso à margem direita do Tietê e ainda próxima à Estação Geral, ao aeroporto e ao porto fluvial, constituindo assim a principal entrada da cidade. Os acontecimentos rememorados pela Ponte Grande são as Bandeiras do século XVIII. Mais uma vez a história inspira o artista na projeção de um monumento, desta vez em homenagem ao passado que marcou a história da cidade - o percurso das Bandeiras. Neste momento seus desenhos se complementam no texto emocionado:

Agora imaginamol-o não á margem, em situação secundária, mas no centro mesmo do rio, como uma grande proa a emergir das águas, voltada para jusante, justamente na direcção do sertão, que o paulista devassou e que é ainda, dentro do Estado, a 'terra prometida' (MAIA, 1930: 351).

Desta vez tal projeto apresenta uma outra linguagem arquitetônica em estilo artdecô ou moderno como ele mesmo se refere. Os Pilones e o monumento principal reduzem-se a uma casca de pedra ou granito sobre esqueleto de cimento armado.

Tudo liso e simples, o que fará valer as esculpturas. Mas

URBANA, ano 2, no 2, 2007, Dossiê: Cidade, Imagem, História e Interdisciplinaridade. 
não a nudez ou a esteril abstenção decorativa do pseudo racionalismo. Como diz o professor de Viena, 'todo necessario é bonito, nem todo o superfluo é feio'. (MAIA, 1930: 355)

Na condição de arquiteto, urbanista e político, as palavras e as imagens de Prestes Maia no Plano de Avenidas indicavam ao leitor uma direção - a transformação da cidade em futura metrópole. Nesta perspectiva a bravura dos Bandeirantes representava o símbolo do trabalho, da riqueza e a conquista política e econômica de São Paulo perante as demais cidades brasileiras. Importa ressaltar que essas imagens "proféticas" atravessaram os anos 1950, e foram utilizadas por diferentes discursos no sentido de justificar o crescimento acelerado, representado pelo slogan da "cidade que mais cresce no mundo", ou o chamado "fenômeno urbano".

Embora tenha realizado grande parte da sua proposta viária, o único exemplar arquitetônico construído foi a ponte das Bandeiras, já os outros "figurinos" apresentados não correspondiam com as imagens projetadas para a capital no decorrer da implantação do Plano. ${ }^{3}$ Entretanto, como poucos planejadores de cidades no mundo, Prestes Maia buscou a perfeição ao integrar em sua formação os lados científico, político e artístico. Este foi o motivo do descompasso entre a linguagem discursiva e a projetual como diria a arquiteta Maria Cristina Leme, e vários estudiosos do Plano de Avenidas. No entanto, aqui nós podemos entendê-lo como parte dos caminhos que atravessam a relação entre a razão e a paixão. E nesta perspectiva, concluir que enquanto a história representou a fonte de inspiração para as projeções arquitetônicas, e esta por sua vez significou o veículo transmissor da expressão sentimental, a história foi o

\footnotetext{
${ }^{3}$ O jornal A Gazeta, 25-08-1954, apresenta uma propaganda com os seguintes dizeres: " $\mathrm{Na}$ prefeitura sob a sua administração Prestes Maia fez de São Paulo antiquado a cidade mais bela da America do sul. Prestes Maia transformou a paulicéia ao fazer isto: No Centro: as avenidas Ipiranga e Anhangabaú; as reformas da praça da República, das ruas São Luiz, Maria Paulo e Anita Garibaldi, do Parque Pedro II e da ladeira do Carmo; os melhoramentos das ruas Senador Queiroz, Mercúrio, Santa Rosa, Vieira de Carvalho, Xavier de Toledo e da Liberdade; a remodelação do Piques e do parque Anhangabaú; a abertura da praça do Carmo; a ampliação das praças João Mendes e Clovis Bevilaqua; a modernização das praças Ramos de Azevedo do Patriarca e do Arouche. Nos Bairros: a Av. Nove de Julho; a canalização do Tietê; abertura e construção das praças Cornélia, na Agua Branca, Guianas, no Jardim America, Fernando Prestes, na Luz, Rudge, no Tatuapé, General Polidoro, na Aclimação, Nossa Senhora da Aparecida, em Indianopolis, Nossa Senhora da Conceição, no Cambuci, e Anajás, no fim da avenida Brigadeiro Luiz Antonio; o bosque publico, junto ao Museu do Ipiranga; o prolongamento das avenidas Paulista, Pacaembú, Rebouças, Rangel Pestana e Anhangabaú, (inferior); os jardins do Trianon e da alameda Jaú; a conclusão e alrgamento da avenida São João; a avenida do Café, ligando a avenida Jaguaré, entre a Lapa e a estrada de Osasco. Etc., etc., etc.
}

URBANA, ano 2, no 2, 2007, Dossiê: Cidade, Imagem, História e Interdisciplinaridade. 
fio condutor capaz de justificar as intervenções técnicas presente no Plano de Avenidas.

Assim como no Plano de Avenidas, também encontramos nos dias atuais diferentes projetos que procuram reapropriar do passado na tentativa de transformar degradados sítios históricos em áreas de entretenimento urbano e consumo cultural. Nossa intenção é trazer a contribuição da história, no sentido de chamar a atenção dos urbanistas para que os cenários românticos de praças não sejam transformados em mercadoria de um passado ilusório, ou ainda fazer da história a parceira crítica do tempo, capaz de revelar na materialidade do construído as marcas de conflito e a capacidade criativa de projetar, sem desistir de sonhar com o sentido humano de cidade.

\section{Referências Bibliográficas}

AGACHE, Alfred (1926). Cidade do Rio de Janeiro: extensão e embelezamento. Organizações projectadas pela administração de Antônio Prado Jr. AMD.P.LG-S.F.U, Foyer Brésilien.

AZEVEDO, Haroldo (1958). A cidade de São Paulo. vol. I, II, III, IV. São Paulo: Companhia Editora Nacional.

BRESCIANI, Maria Stella (1990). Permanência e Ruptura no Estudo das Cidades. In: FERNANDES, Ana e GOMES, Marco Aurélio A. de Filgueiras (Org.) Cidade \& História - modernização das cidades brasileiras nos séculos XIX e XX. Salvador: UFBA.

CALVINO, Ítalo (1991). As cidades invisíveis, São Paulo: Companhia das Letras.

CAMPOS, Eudes (1996). Cidade. São Paulo na visão classista de Prestes Maia, Revista do Patrimônio Histórico Secretaria Municipal de Cultura, Ano III.

CARPINTÉRO, Marisa Varanda Teixeira (1998). Em busca da Imagem: a cidade e o seu figurino (São Paulo 1938-1954). Tese (Doutorado em História). Campinas: Instituto de Filosofia e Ciências Humanas da Universidade Estadual de Campinas. CORTESÃO, Jaime (1958). Rapôso Tavares e a Formação Territorial do Brasil. Rio de Janeiro.

LE CORBUSIER (1971). Planejamento Urbano, São Paulo, Perspectiva.

LE CORBUSIER (1992). Urbanismo, São Paulo, Martins Fontes.

URBANA, ano 2, no 2, 2007, Dossiê: Cidade, Imagem, História e Interdisciplinaridade. 
LEME, Maria Cristina (1990). "O Plano de Avenidas e a formação do pensamento urbanístico em São Paulo nas três primeiras décadas do século XX". In GOMES, Marco Aurélio Filgueiras e FERNANDES, Ana (Org.). Cidade \& História. UFBA.

LEME, Maria Cristina (1990) Revisão do Plano de Avenidas - Um estudo sobre o Planejamento Urbano, Tese apresentada à Faculdade de Arquitetura e Urbanismo da Universidade de São Paulo para obtenção do título de Doutor.

MAIA, Francisco Prestes, (1930) Estudos de um Plano de Avenidas para a cidade de São Paulo, São Paulo, Melhoramentos.

MOBEIG, Pierre (1958). Aspectos Geográficos do Crescimento de São Paulo, Ensaios Paulistas, Editora Anhambi, S/A, São Paulo.

MUNFORD, Lewis (1952) Arte e técnica. São Paulo, Martins Fontes.

SHORSCKE, Carl (1988) Viena Fin-de-siècle, Campinas, Editora Unicamp, São Paulo, Companhia das Letras.

Texto recebido em 24/09/2007. 